\title{
FEATURES OF OCCLUSAL CORRELATIONS OF MOLARS IN THE DENTAL CLINIC
}

DOI: 10.36740/WLek202105115

\author{
Petro A. Hasiuk', Anna B. Vorobets ${ }^{1}$, Andrii Ye. Demkovych ${ }^{1}$, Iryna M. Tkachenko², Oksana V. Klitynska ${ }^{3}$, \\ Svitlana 0. Rosolovska' ${ }^{1}$, Lyudmila V. Pyasetska ${ }^{1}$ \\ II. HORBACHEVSKY TERNOPIL NATIONAL MEDICAL UNIVERSITY, TERNOPIL, UKRAINE \\ 2UKRAINIAN MEDICAL STOMATOLOGICAL ACADEMY, POLTAVA, UKRAINE \\ ЗUZHHOROD NATIONAL UNIVERSITY, UZHHOROD, UKRAINE
}

\begin{abstract}
The aim: To study the odontoglific and odometometric parameters of molar crowns of the upper and lower jaws in males and females.

Materials and methods: To achieve the aim of the research was used odontoglyphic, odometometric and statistical methods of research.

Results: We have found that male molars of the upper jaw are characterized by approximately the same ratio between the vestibular-palatal and mesial-distal diameters of the crown, so the teeth are square-formed. For female large angular teeth of the upper jaw the predominance of vestibular-palatal over mesial-distal diameters of the crown is characteristic, which results in an oval form of the teeth. On having analyzed the forms of the third lower molars, it can be affirmed that for this group of teeth various variational forms of crowns, from three- to five-tuber forms, are characteristic. Vestibular-lingual and mesio-distal sizes also vary according to the type of odontoglific pattern of occlusal crown surface.

Conclusions: We consider it expedient to take into account the abovementioned characteristics of the masticatory surface of molars of the upper and lower jaws of male and female persons for the creation of qualitative orthopedic structures that would fully restore the masticatory function.
\end{abstract}

KEY WORDS: teeth; molars; occlusal surface; masticatory function

Wiad Lek. 2021;74(5):1130-1133

\section{INTRODUCTION}

Modern methods of prosthetic treatment with non-removable orthopedic constructions include the restoration of the natural configuration and the sizes of the occlusal surface of the missing teeth, in consideration of the functional state of the masticatory apparatus $[1,2,3]$. In this case, a large number of differences in the anthropometric indices of teeth and jaws in representatives of different sexes, races and nationalities is observed $[4,5,6]$. Similar data are needed to more effectively restore the natural form of occlusal surface of the teeth, which is especially important when constructing bridge-like prosthetics. In orthopedic treatment of dental rows defects, taking into account the average sizes of teeth crowns and their sex affiliation will help to accurately simulate the occlusal surface of the prosthesis, which will promote the correct restoration of occlusal contacts, which provide the optimal direction of the functional axes of the supporting teeth, and effective recovery of the masticatory function.

\section{THE AIM}

To study the odontoglific and odometometric parameters of molar crowns of the upper and lower jaws in males and females.

\section{MATERIALS AND METHODS}

This study was conducted at the orthopedic dentistry department I. Horbachevsky Ternopil National Medical University, Ukraine, and was approved by the ethics committee of the I. Horbachevsky Ternopil National Medical University, which determined that the general ethical rules of humane treatment of patients were observed when working with patients in accordance with the requirements of the Tokyo Declaration of the World Medical Association and the International Recommendations of the Helsinki Declaration of Human Rights.

To achieve the objective we used odontoglyphic, odometometric and statistical methods of research. We conducted a clinical dental examination of 250 persons of both sexes, within which the odontological status based on the odontoglific pattern of the occlusal surface of the molars was assessed separately in male and female. All the examined patiens were residents of Ternopil and Ternopil region. For odontometric analysis 50 persons without dental rows defects were selected from the total number of patients, including 25 males and 25 females, with intact molars, which had an explicit anatomical form of crown. Odontometric research was carried out in accordance with the methodology described by $\mathrm{M}$. Nouri $[7,8]$. 


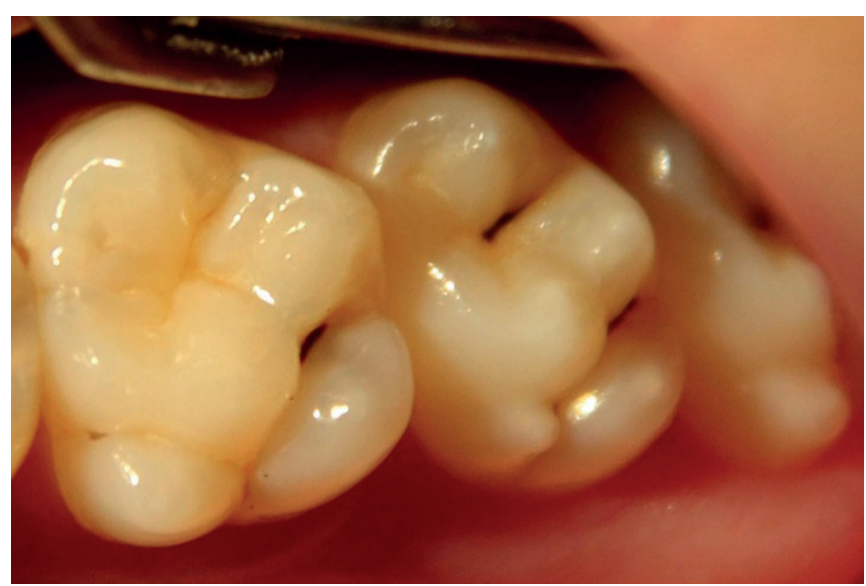

Fig. 1. The Carabelli's tubercle on the first and second upper molars.



Fig. 2. Three humpback forms of the third molar of the upper jaw.

\section{RESULTS AND DISCUSSION}

As a result of the study of the basic odometometric parameters of molar crowns, we have established the average values of these indices for the upper and lower molars of males and females.

Masticatory surface of the first molar of the upper jaw is formed by four tubers, which form Y-four type of odontoglyfic pattern. The crown height varies from 6.67 to 6.81 $\mathrm{mm}$ in males and from 5.89 to $5.94 \mathrm{~mm}$ in females. The vestibule-lingual size is $11.4 \mathrm{~mm}$ (male) and $10.7 \mathrm{~mm}$ (female). The value of the mesio-distal crown size is $10.4 \mathrm{~mm}$ and $10.24 \mathrm{~mm}$, respectively, in male and female.

As a result of odontoglyphic study, we have found that for all molars of the maxilla and the first molar of the mandible is characteristic the presence of a continuous distal crest

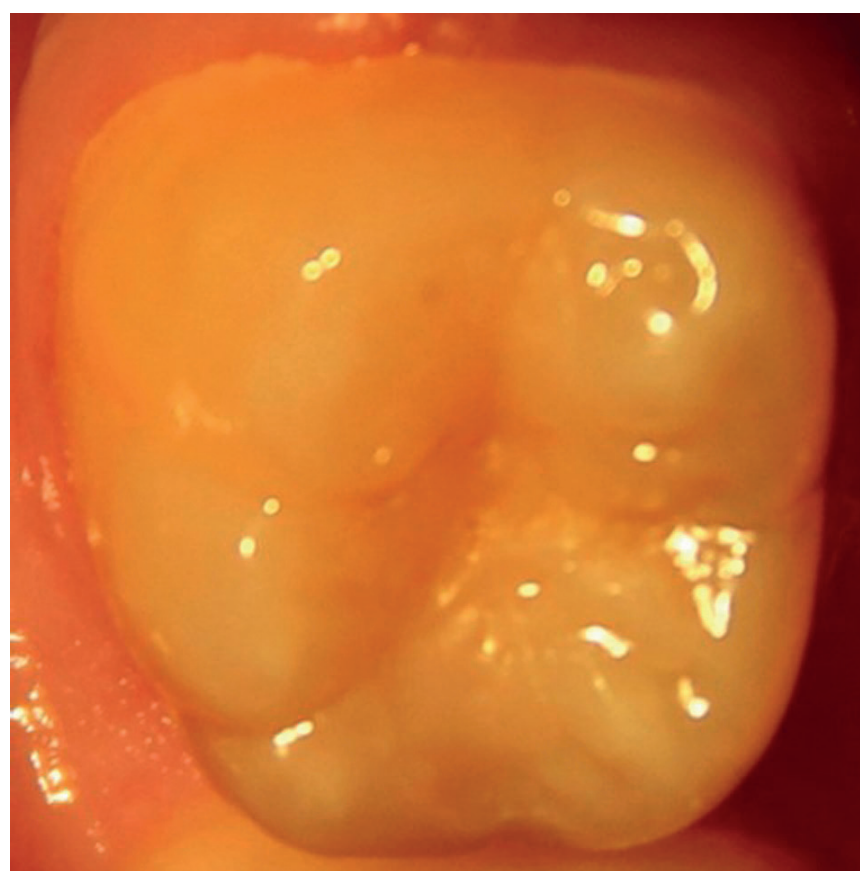

Fig. 3. The first molar of the lower jaw.



Fig. 4. Plus-four types of odontoglyphic pattern of the occlusal surface of the crown of the second molar of the lower jaw. 
of the trigon, which forms the Y-type of odontoglyphic pattern and is considered to be an archaic sign. This results are confirmed by the work of a number of authors $[9,10,11,12]$. As a result of our study, we also found out that on the second and third molars of the mandible, it is separated by a central groove. Often, cases of lowering the distal crest in the center of the crown were observed. Its highest part is an edge that connects the epiconus and the diaconus. During our study, two variants of the formation of a distal crest of the trigon were established: in the first variant it was formed due to the merger of the distal crests of the epiconus and the diaconus. In the second variant it was formed by the connection of the distal crest of the epiconus with the central crest of the diaconus.

At the border of the lingual and medial surface of the upper molar crowns on the lateral surface of the eoconus is located a styloid additional Carabelli's tubercle (Fig. 1).

During the study, it was determined that this formation can considerably vary according to the degree of its development. In this case, the crown may change its shape due to the increase of the vestibular-palatal crown size. In the least developed form, it is represented by an insignificant swelling of the enamel, separated by one or two grooves. With a more pronounced form, this formation has a distinct vertex, which is separated from the surface of the eoconus by an arched groove. The strongly manifested Carabelli's tubercle almost reaches the height of the masticatory surface and corresponds to the size of the main tubers of the masticatory surface. It is worth pointing out that the presence of the Carabelli's tubercle was observed in the upper molars of males. In addition, in some cases, we noted its presence on the first and second molars of the upper jaw.

In female molars, we noted that Carabelli's tubercle is almost not found. This fact can be explained due to the predominance of reduction processes in female teeth. At the same time, the simplicity of the crown structure occurs due to the reduction of the mesial-distal diameter of the crowns of this group of teeth in relation to the vestibular-palatal, due to the reduction of the palatal-distal tuber.

The crown of the second molar of the upper jaw is also represented by four tubers. The value of crown height in men and women is $6.3 \mathrm{~mm}$ and $5.5 \mathrm{~mm}$ respectively. Average values of the vestibule-lingual size are $11.2 \mathrm{~mm}$ (male) and $10.5 \mathrm{~mm}$ (female). The values of the mesio-distal crown size are $9.5 \mathrm{~mm}$ and $9.3 \mathrm{~mm}$, respectively, in males and females.

The third molars of the upper jaw can considerably vary in their shape and size accordingly. During the conducted odontoglific study it was found out that male persons appear to have four-tuber forms of the specified teeth. It should be noted that three-tuber forms of crowns were more common in female persons. With this type of structure, only the main tubers of the trigon are manifested. The tubers of the coupon system are reduced, which is manifested by the thickening of the distal contour of the crown. The diastolic division of the contour of the crown is rounded, as if it were cut. The vestibule-lingual size of the crown is
$5.4-5.6 \mathrm{~mm}$ in males and $4.7-4.8 \mathrm{~mm}$ in females. The values of the mesio-distal crown size are $8.4 \mathrm{~mm}$ and 7.6 $\mathrm{mm}$, respectively, in males and females. The crown height is $5.5 \mathrm{~mm}$ (male) and $4.7 \mathrm{~mm}$ (female) (Fig. 2).

The first molar of the mandible has an asymmetrical crown with a protruding epiconus and a displaced vestibular eoconus. The tubers of the masticatory surface often form an Y-five pattern. Mesio-distal crown size is $10.6 \mathrm{~mm}$ (male) and $10.3 \mathrm{~mm}$ (female). Values of the vestibule-lingual crown size are as follows: $10.4 \mathrm{~mm}$ - for male and 10.2 $\mathrm{mm}$ for female persons. We have found that the height of the crown varies from 6.5 to $6.2 \mathrm{~mm}$, respectively, in men and women (Fig. 3).

In the course of the study we revealed sex differences in the types of odontoglyphic pattern of the occlusal surface of the crowns of second lower jaw molars. So, for the specified group of teeth in females is mostly common a plus-four type of the pattern, while in males it is an Y-five or Y-four pattern. This provision indicates the predominance of the processes of reduction of teeth crowns in female subjects. In the plus-four type there is a discontinuous course of the distal crest of the trigon, while the central crest is well developed. We noted that in this type of odontoglific pattern the crown has a clearly manifested quadrilateral form, without rounding of the distal division. The crown height varies from 5.5 to $5.9 \mathrm{~mm}$, respectively, in men and women (Fig. 4).

On having analyzed the forms of the third lower molars, it can be affirmed that for this group of teeth various variational forms of crowns, from three- to five-tuber forms, are characteristic. Vestibular-lingual and mesio-distal sizes also vary according to the type of odontoglific pattern of occlusal crown surface.

We have found that male molars of the upper jaw are characterized by approximately the same ratio between the vestibular-palatal and mesial-distal diameters of the crown, so the teeth are square-formed. For female large angular teeth of the upper jaw the predominance of vestibular-palatal over mesial-distal diameters of the crown is characteristic, which results in an oval form of the teeth.

\section{CONCLUSIONS}

We consider it expedient to take into account the abovementioned characteristics of the masticatory surface of molars of the upper and lower jaws of male and female persons for the creation of qualitative orthopedic structures that would fully restore the masticatory function.

\section{REFERENCES}

1. Fernandes L., Veloso C., Oliveira J. Odontometric analysis of molars for sex determination. Braz J Oral Science. 2016;15(1):35-38.

2. Hasiuk P., Vorobets A., Hasiuk N. et al. Sex differences of odontometrical indexes crowns of molars. Interventional Medicine and Applied Science. 2017;9(3):160-163.

3. Zorba E., Spiliopoulou C., Moraitis K. Evaluation of the accuracy of different molar teeth measurements in assessing sex. Forensic Sci Med Pathol. 2013;9(1):13-23. 
4. Morita W., Morimoto N., Ohshima H. Exploring metameric variation in human molars: a morphological study using morphometric mapping. J Anat. 2016;229(3):343-355.

5. Kalashnikov D., Hasiuk P., Vorobets A. et al. Features of the course of enamel biomineralization processes in various anatomical areas of the tooth. Wiadomosci lekarskie. 2020;73(5):864-867.

6. Macaluso P. Investigation on the utility of permanent maxillary molar cusp areas for sex estimation. Forensic Sci Med Pathol. 2011;7(3):233247.

7. Nouri M., Abdi A., Farzan A. Measurement of the buccolingual inclination of teeth: manual technique vs 3-dimensional software. Am J Orthod Dentofacial Orthop. 2014;146(4):522-529.

8. Nouri M., Hosseini S.K., Asefi S. et al. Three-dimensional measurement of tooth inclination: A longitudinal study. Dent Res J (Isfahan). 2019;16(4):225-232.

9. Eraydina F., Cakana D.G., Tozlua M. et al. Evaluation of buccolingual molar inclinations among different vertical facial types. Korean J Orthod. 2018:48:333-338.

10. Macaluso P. Sex discrimination potential of permanent maxillary molar cusp diameters. J Forensic Odontostomatol. 2010;28(1):22-31.

11. Martins Filho I., Lopez-Capp T., Biazevic M. Sexual dimorphism using odontometric indexes: Analysis of three statistical techniques. J Forensic Leg Med. 2016;44:37-42.

12. Yanishen I., Tkachenko I., Skrypnikov P. et al. Wear resistance of dental materials which are used for anterior teeth restorations. Wiadomości Lekarskie. 2020;73(8):1677-1680.
The work is a fragment of the research work of the orthopedic dentistry department I. Horbachevsky Ternopil National Medical University "Multidisciplinary approach to the study of the pathogenesis and treatment of main dental diseases based on the study of mechanisms of damage to the tissues of the oral cavity against the background of concomitant somatic pathology» (State Registration No. 0119U002431).

\section{ORCID and contributionship:}

Petro A. Hasiuk: 0000-0002-2915-0526 ${ }^{A}$

Anna B. Vorobets: 0000-0002-4119-7896 D

Andrii Ye. Demkovych: 0000-0001-9823-4283 ${ }^{F}$

Iryna M. Tkachenko: 0000-0001-8243-8644 ${ }^{B}$

Oksana V. Klitynska: 0000-0001-9969-2833 ${ }^{\mathrm{C}}$

Svitlana O. Rosolovska: 0000-0003-4768-3905 ${ }^{\mathrm{E}}$

Lyudmila V. Pyasetska: 0000-0002-5640-2258 ${ }^{\mathrm{C}}$

\section{Conflict of interest:}

The Authors declare no conflict of interest.

\section{CORRESPONDING AUTHOR \\ Anna B. Vorobets}

I. Horbachevsky Ternopil National Medical University

$1 \mathrm{~m}$.Voli St., 46001 Ternopil, Ukraine

tel: +380968783459

e-mail: vorobecab@tdmu.edu.ua

Received: 09.12.2020

Accepted: 29.03 .2021

A - Work concept and design, B - Data collection and analysis, C - Responsibility for statistical analysis, D-Writing the article, $\mathbf{E}$ - Critical review, $\mathbf{F}$ - Final approval of the article 